\title{
Propositional Proofing Techniques application in Algebraic Structure Research
}

\author{
Muhamad Ali Misri* \\ IAIN Syekh Nurjati Cirebon, West Java, 45132, Indonesia.
}

*Corresponding author: Sunyaragi, Cirebon, West Java, 45132, Indonesia. e-mail addresses: alimisri@syekhnurjati.ac.id

\section{article i nfo \\ How to cite this article: \\ Misri, M., A,. (2020). Propositional Proofing Techniques application in Algebraic Structure Research. Eduma: Mathematics Education Learning And Teaching, 9(1), 1 - 13. \\ doi:http://dx.doi.org/10.24235/eduma.v9i1.5624}

Article history:

Received: 12 09, 2019

Accepted: 02 17, 2020

Published: 07, 2020

Copyright $(\mathrm{C}) 2020$

EduMa: Mathematics Education Learning and Teaching under the Creative Commons Attribution 4.0 International License.

\section{a bstract}

PROPOSITIONAL PROOFING TECHNIQUES APPLICATION IN ALGEBRAIC STRUCTURE RESEARCH. This paper investigates proofing techniques which are used in algebraic structure research and how to apply those techniques. This paper also investigates the reasoning behind the application of the techniques and their effects. The data was collected by reviewing some algebraic structure textbooks used recently. Books reviewed were domestic and foreign books. The results of the review process were noted and documented, and then finally transcribed and coded. The review process of each book was carried out twice. The data obtained were then triangulated, to get the valid data, and eventually used for further analytical purposes. The results obtained show that not all the proofing techniques were used in the proofing process in the algebraic structure research. They tended to use the same technique in every proofing activity. This might be due to mastery of proofing techniques, preferences for certain proofing techniques, lack of information about the development of various proofing techniques. The resulting impact can be identified from the steps of proofing, meanwhile, if it is conducted using another technique, it can reduce the steps, is more acceptable also comprehensible.

\section{Keywords:}

Algebraic structure research, proofing technique, triangulated methods.

\section{Open Access}




\section{INTRODUCTION}

Each student takes a course on proofing techniques before they take a proofingoriented course such as: real analysis and abstract algebra. In that course, they spend time practicing to master the mechanisms of proof and writing it formally. Moreover, they learned various techniques in proof from the reference book. The experience gained will determine success in proofing-oriented advanced courses.

Many proofing techniques have been discovered and used (Daepp \& Gorkin, 2011). This technique is very helpful for researchers, writers and lecturers of algebraic structure in writing formal proof (Hungerford, 2014; Gallian, 2017; Misri, 2017). The more diverse techniques used in each proposition that will be proven, of course, really helps undergraduate students skilled in proofwriting and applying it in algebraic structure courses (Lee, 2016; BleilerBaxter \& Pair, 2017; Brown, 2017; Yan, 2019), likewise with lecturers/ mathematicians in capturing the contents of undergraduate students' proofs (Miller, Infante, \& Weber, 2017). This paper aims to investigate the diversity of proofing techniques and their effects on students' skills in applying them.

In this research, the book which is used as a reference in the algebraic structure research is observed to obtain the many types of proofing techniques used. In this observation, the diversity of techniques used in proving obtained. Furthermore, observations were made to a number of students who conducted an algebraic structure study using that reference textbook. Observations were made to see the understanding and mastery of students in using the proofing techniques. Finally, an analysis is carried out to see the contribution of using various techniques in developing student skills in applying the proofing techniques.

\section{LITERATURE REVIEW}

Proof basically makes a series of deductions from statements (propositions) in the form of axioms, definitions and propositions that already exist (lemmas, theorems, or corollary). The proof is carried out to obtain the truth of a proposition to provide confidence in its users. The proof is written in a formal form using techniques that have been recognized for validity.

Proof in mathematics shows several functions including:

1. Verification: validating the truth

2. Explanation: answering the question "why?"

3. Conviction: removes doubts

4. Systematization: adjusting mathematical results into a broader context

5. Discovery: inventing new results

6. Communication: transmit mathematical knowledge and understanding

7. Enjoyment: meeting an intellectual challenge elegantly

Proofing is carried out to validate the truth. As long as conclusions follow from hypotheses, the verified propositions are said to be true regardless of their aesthetic form and appeal.

Proof is more satisfying if it not only shows the truth of the statement, but also helps to understand why the statement is true. To do this, explanations are needed by utilizing mathematical properties that are well known and understood. When providing explanations, evidence can also contribute to systematization by bringing about a fundamental relationship that places results in a broader context.

A demonstration is enough for verification. However, demonstrations cannot always reduce doubts. The best is when proof can convince the reader that it is true. For convincing purposes, proofs usually involve rigorous arguments and sketches of inferences. In completely 
rigorous proof, the basic arguments needed to convince can be obscured by the level of detail. On the other hand, sketches that are too short, while showing the general structure of the argument, can make the reader doubtful about the validity of the steps given. To be convincing, the evidence must be clear and complete, it does not have to be too detailed. The right balance is needed to get a judgement.

Another proof function is to bring mathematical results into wider knowledge. In carrying out this function, evidence can provide results that were initially considered to be unrelated or do not have the same structure based on the same assumptions. Thus, the evidence can help expose the underlying axiomatic structure. Investigating the systematic aspects of evidence, as we have seen, has led to the development of alternative axiomatic systems and insights on the axiomatic system in general. By placing the results in a broader context, of course, systematization can also facilitate their communication.

Although discovering new mathematical truths is not always related to the proof, building that proof can pave the way to discovery. In addition, given the nonintuitive subject matter, the only way to explain unexpected results through a proof is to go ahead blindly with a series of logical inferences. The proof is made indeed to direct mathematicians to new truths, because the proof has offered new insights into the fundamental properties underlying the objects involved. For this reason, the proof is written to reveal a totally new area to be investigated.

Presenting and publishing evidence is the main way in which a mathematician communicates with others. In this function, the proof is basically used to convey assumptions made, definitions and rules for drawing conclusions used, as well as theorems that must be proven. Among mathematicians, the most useful proof for communication is in the explanation of the subject matter. In addition, the proof can reveal the habits of the writer's mind and the intellectual tools and resources they use. For this reason, proof can be useful in communicating with other mathematicians when providing an understanding of the thought processes that lead to its creation. Different evidentiary styles, and different levels of accuracy, are maintained in the history of mathematics to inform about the social process of communicating mathematical knowledge.

Evidence can evoke responses similar to those caused by good art. Mathematicians really enjoy their mathematical knowledge by reading and making evidence. The proof that meets intellectual challenges is very pleasing. Moreover, they are challenged to first verify the propositions that are the basis for proof and apparently have no mathematical implications. Regardless of the topic of their study, mathematicians think that some proof is inherently better than others, namely proof not only for showing, but also for expressing, explaining and finally convincing. Mathematicians value brief proof in the sense that it requires fewer assumptions that people might think of. However, mathematicians often talk about qualities that are difficult to understand, known as beauty or elegance. The most pleasant proof, in the eyes of mathematicians, can be revealed, concise, and unexpected.

There are six techniques in proving that are of concern to this paper, namely: direct proof, contraposition method, proving by contradiction, proving by mathematical induction, construction method and proving the equivalent statement.

Direct Proof. This technique just uses the right forward flow, using logical implications, starting from the statement of the hypothesis/ antecedent to the conclusion/ conclusion. Furthermore, this technique also uses basic decision rules such as: ponens mode, tollens mode and syllogism as well as reimbursement rules. 
Direct Proof Steps.

To prove the statement form $P \rightarrow Q$ is correct, do the following steps:

1. Assume hypothesis $P$ is correct.

2. Find a series of statements such as $P_{1}, P_{2}, \cdots, P_{n-1}, P_{n}$ so that $P \Rightarrow P_{1}, P_{1} \Rightarrow$ $P_{2}, P_{2} \Rightarrow P_{3}, \cdots, P_{n-1} \Rightarrow P_{n}, P_{n} \Rightarrow Q$.

3. Use the basic rules of logical inferences and substitution to get all the implications.

4. Use the ponens mode rule so that a true $Q$ conclusion is obtained

Example 1. Prove that for all $x$ integers, if $x$ is an odd number then $x^{2}$ is also an odd number.

Proof:

Let $x$ an odd integer.

$\Rightarrow$ there exist $n$ such that $x=2 n+1$, $n$ an integer.

$$
\begin{aligned}
& \Rightarrow x^{2}=(2 n+1)^{2} \\
& =(2 n)^{2}+4 n+1 \\
& =2\left(2 n^{2}+2 n\right)+1 \\
& \Rightarrow x^{2}=2 m+1 \text { where } m=2 n^{2}+ \\
& 2 n \text {. } \\
& \therefore \quad x^{2} \text { is also odd. }
\end{aligned}
$$

Contraposition Method. To show the implication statement form " $P \rightarrow Q$ " is true, by considering each implication is equivalent to the contraposition, we only need to prove " $\neg Q \rightarrow \neg P$ " is true.

Contraposition Method Step.

To prove the statement form is correct using this method, do the following steps:

1. Assume hypothesis $\neg Q$ is correct.

2. Find a series of statements such as $Q_{1}, Q_{2}, \cdots, Q_{n-1}, Q_{n}$ such that yields $\neg Q \Rightarrow Q_{1}, Q_{1} \Rightarrow Q_{2}, Q_{2} \Rightarrow Q_{3}, \cdots$ $, Q_{n-1} \Rightarrow Q_{n}, Q_{n} \Rightarrow \neg P$.

3. Use basic logic inferences and substitutes to get all the implication.

4. Use the ponens mode rule so that a true $\neg P$ conclusion is obtained.

Example 2. Show that for all $x$ integers, if $x^{2}$ is an odd number then $x$ is also an odd number.

\section{Proof:}

Let $x$ an integer but not odd.

$\Rightarrow$ there exists integer $n$ such that $x=2 n$
$\Rightarrow x^{2}=(2 n)^{2}$

$$
=2\left(2 n^{2}\right)
$$

$\Rightarrow x^{2}=2 m$ where $m=2 n^{2}$

$\Rightarrow x^{2}$ is also not odd.

$\therefore$ for all $x$ integers, if $x^{2}$ is an odd number then $x$ is also an odd number.

Proving by Contradiction. Consider to show the implication statement "if $P$ then $Q$ " is true, using proof with contradiction. Begins by assuming the premise or hypothesis $P$ is true and applying the opening sentence by assuming that $\neg Q$ is true. Next find a statement that shows that $\neg Q \rightarrow S$ with $S$ a false statement, as opposed. As a result, the $\neg Q$ statement must be wrong. The $\neg Q$ false statement occurs precisely when the $Q$ statement is true. For this reason, the statement $Q$ is true and the statement "if $P$ then $Q$ " is proven to be true.

Proving by Contradiction step:

To prove the statement form $P \rightarrow Q$ is correct, do the following steps:

1. Assume the hypothesis $P$ is correct and apply the opening sentence assuming $\neg Q$ is true.

2. Find a series of statements such as $Q_{1}, Q_{2}, \cdots, Q_{n-1}, Q_{n}$ are all true and the statement $S$ is false such that $\neg Q \Rightarrow$ $Q_{1}, Q_{1} \Rightarrow Q_{2}, Q_{2} \Rightarrow Q_{3}, \cdots, Q_{n-1} \Rightarrow$ $Q_{n}, Q_{n} \Rightarrow S$.

3. Use basic logic inferences and substitutes to get all the implication and hence $\neg Q \Rightarrow S$

4. The proof ends by showing the contradiction of the $S$ statement with the $P$ statement or another true statement.

Proof by Induction. The statement $(n)$ is true for every integer number $n \geq 0$ if:

1. the statement (0) is a true statement; and

2. If the statement $(k)$ is true then the statement $(k+1)$ is also true.

Construction Methods. This method is more appropriate for proving quantifier statements, especially for special (existential) quantifier. To show existence, we need to construct by searching, choosing, forming, thinking 
and so on. Although the example is sufficient to show the existence of a statement, the example will never be able to show the truth of a statement that contains a universal quantifier both directly and indirectly. To deny a statement is enough to give a counterexample.

Proving the Equivalent Statement. To prove the equivalent statement $" \mathcal{P}_{1} \Leftrightarrow$ $\mathcal{P}_{2} \Leftrightarrow \cdots \Leftrightarrow \mathcal{P}_{n}$ " is true, we must prove the implications $\quad \mathcal{P}_{1} \Rightarrow \mathcal{P}_{2}$ ", " $\mathcal{P}_{i} \Rightarrow \mathcal{P}_{i+1}$ ", $\mathcal{P}_{n} \Rightarrow \mathcal{P}_{1}$, are all true for $i \in\{2,3,4,5,6,7\}$.

In understanding a proof, it is very important to be able to capture the key idea in proof. The key idea of proof includes the structure, guidelines and direction, as well as the steps and procedures contained in the proof (Yan, 2019). Yan also underlined the 5 focuses of students in capturing key ideas of the proof. They are on overall structure, mathematical ideas, details, method and diagram-algebra connection.

\section{METHODS}

\section{Participants and Setting}

Participants were 46 undergraduate mathematics students and two lecturers in the algebraic structure at a university in Central Java, Indonesia. Of the 46 participants, some were from mathematics education and the rest were from mathematics. They are undergraduate students who take algebraic structure courses and have taken courses related to proofing techniques.

To ensure confidentiality, each participant is given a code and divided into two classes. Each class is accompanied by lecturers. The selected participants and lecturers are those who use the same reference textbook in learning the proofing techniques and algebraic structure.

In class $\mathrm{A}$, a number of questions were asked to participants about the mastery of the Proofing technique. The treatment is also given with class $\mathrm{B}$. This is done to see the participants' understanding and mastery of proofing techniques application.

In addition to giving questions to participants, observations were also conducted to the reference textbook in the algebraic structure studies to obtain the many types of proofing techniques used. In this observation, the diversity of techniques used in proving obtained. Two sample textbooks (domestic and foreign) were observed.

\section{Data Collection}

Data were collected from three sources: 1) a questionnaire, 2) an observation sheet, and 3) a discussion sheet. Questionnaires and observation sheets were developed to obtain information related to student mastery in applying proofing techniques. Observations were also made on the reference textbook to see the variety of the proofing techniques used by the book. Discussion is carried out to get in-depth information related to the results of the questionnaire and observation.

\section{Data Analysis}

The analysis was carried out to look at the diversity of the proofing techniques in learning textbooks and see how much they contribute to students' skills in applying the proofing techniques.

The observation results of the textbook are processed and presented to see the diversity of the proofing techniques in the learning reference textbook. Furthermore, the observations and students' responses are compared with the results of discussions with lecturers using triangulation techniques to obtain valid data related to student skills. Data are declared valid if there are no differences (Sugiyono, 2011). Furthermore, valid data are analyzed by comparing the results of observations made on the book to obtain conclusions. 


\section{RESULT AND DISCUSSION}

In this study there are two interrelated findings in the skills of applying proofing techniques, the need to refer to textbooks that use various proofing techniques and the importance of trying various techniques for each statement/ proposition. Regarding the last point, students should not focus on just one technique in proving statements.
The diversity of proofing techniques in a textbook

Observations conducted in two books, foreign and domestic. The multiplicity of each proofing technique in both textbooks were observed and recorded. The diversity of proofing techniques is presented in Table 1.

Table 1

The Various Proofing Technique in a Foreign and Domestic Textbook

\begin{tabular}{lcccc}
\hline \multirow{2}{*}{\multicolumn{1}{c}{ Proofing Techniques }} & \multicolumn{2}{c}{ Multiplicities in Textbook } & \multicolumn{2}{c}{ Percentage } \\
\cline { 2 - 5 } & Foreign & Domestic & Foreign & Domestic \\
\hline Direct proof & 224 & 43 & 82.96 & 72.88 \\
\hline Contraposition & 3 & 1 & 1.11 & 1.70 \\
\hline Contradiction & 19 & 7 & 7.04 & 11.86 \\
\hline Mathematical induction & 11 & 2 & 4.08 & 3.39 \\
\hline Proof by construction & 8 & 1 & 2.96 & 1.69 \\
\hline Equivalent statement proofing & 5 & 5 & 1.85 & 8.48 \\
\hline
\end{tabular}

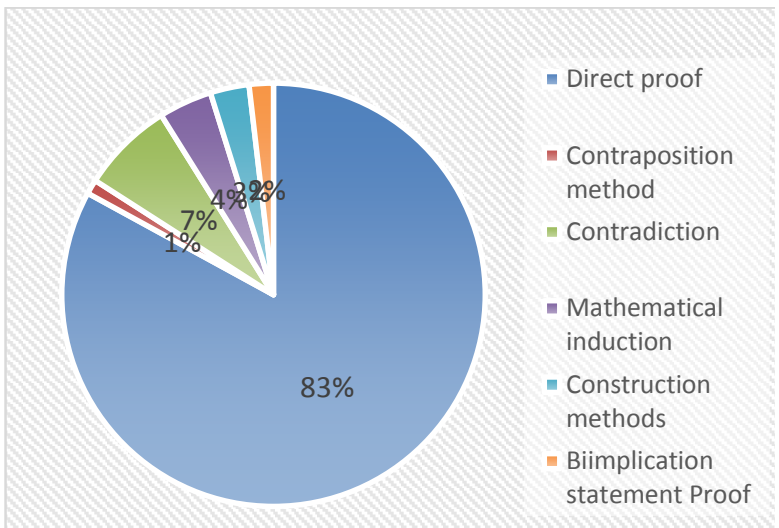

Figure 1. The Various Proofing Technique in a Foreign Textbook

Based on Table 1, it can be stated that most types of proof that are often used are direct proof techniques. This has an impact on the reader's knowledge of these techniques that are rarely used. Furthermore, the impact on their mastery and application

Mastery of proofing techniques and their application in the proving process

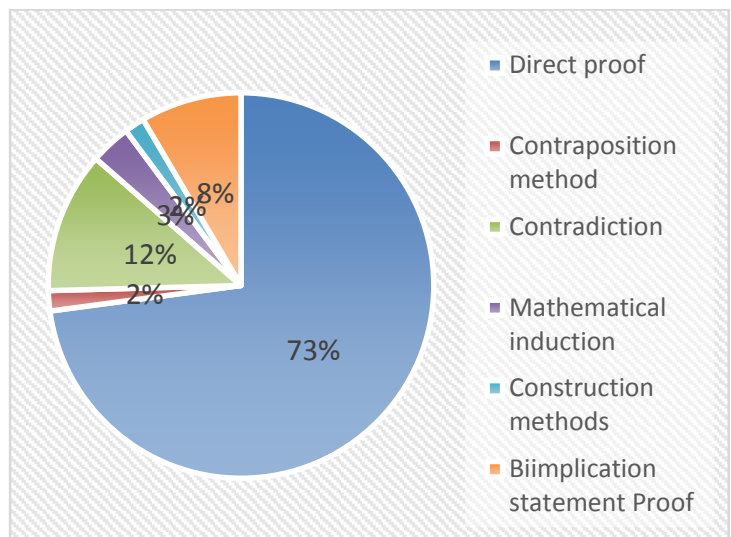

Figure 2. The Various Proofing Technique in a Domestic Textbook

Before observing students' level of proof techniques understanding, we need to see how close these terms are to themselves. For detail, see Figure 3.

The table shows that all students are familiar with all the proofing techniques. This indicates them to understand all of these techniques. Understanding the concept of each technique is crucial to mastering the technique when applying it. 


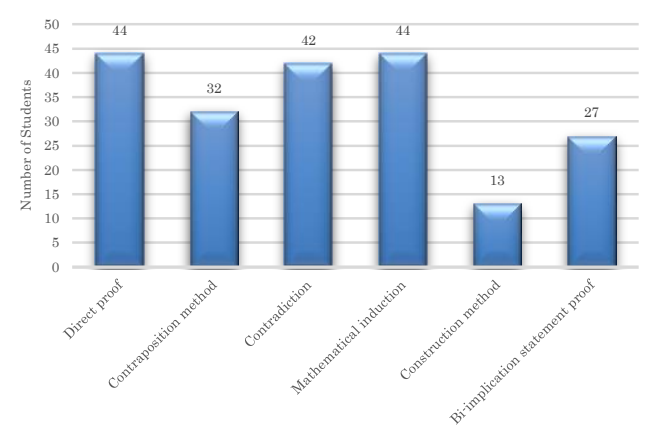

Proofing techniques understanding level can be found in Figure 4. Meanwhile, students' skills in applying the proof techniques, i.e. mastering the techniques, can be found in Figure 5 .

Figure 3. Proofing Techniques Familiarity

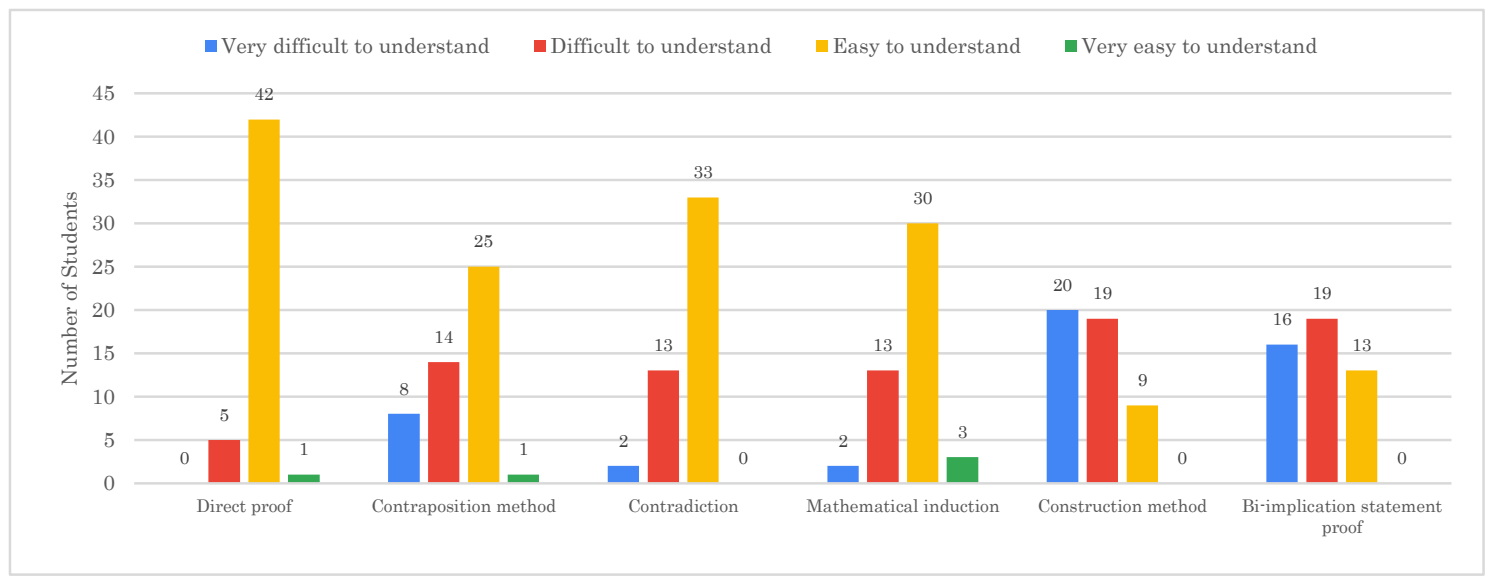

Figure 4. Proofing Techniques Understanding Level

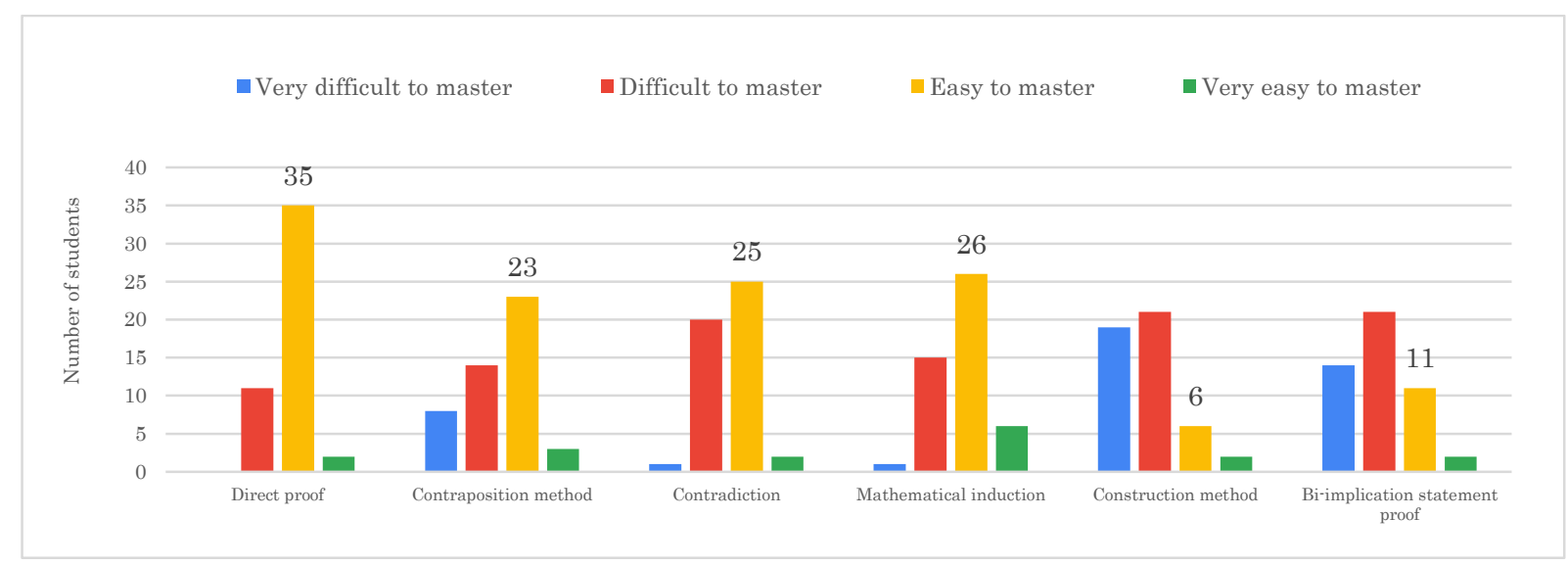

Figure 5. Proofing Techniques Mastery Level

Based on Figure 4 and Figure 5, most students easily understand the techniques of direct proof, contraposition and contradiction, see Figure 4. This is according to the text books they read. On the contrary, proof by construction and equivalent statement proofing techniques is difficult to understand since the textbooks they read lack information related to this proofing technique.

Levelling for each proofing techniques understanding and mastery can be found in following figures. 
Direct Proof Technique Understanding Level

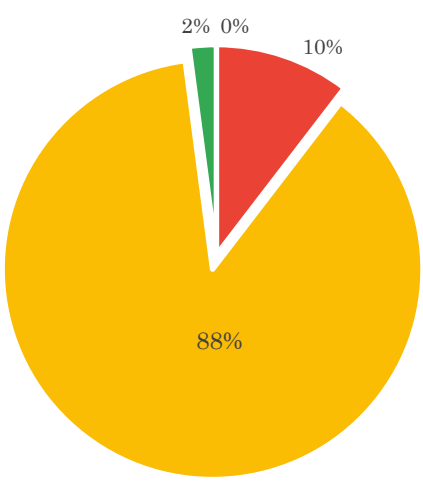

- Very difficult to understand - Difficult to understand

- Easy to understand

- Very easy to understand

Figure 6. Level of Direct Proof Technique Understanding

Based on Figure 6, most students easily understand the direct proofing technique. There are only a few students have difficulty understanding this type of proofing technique.

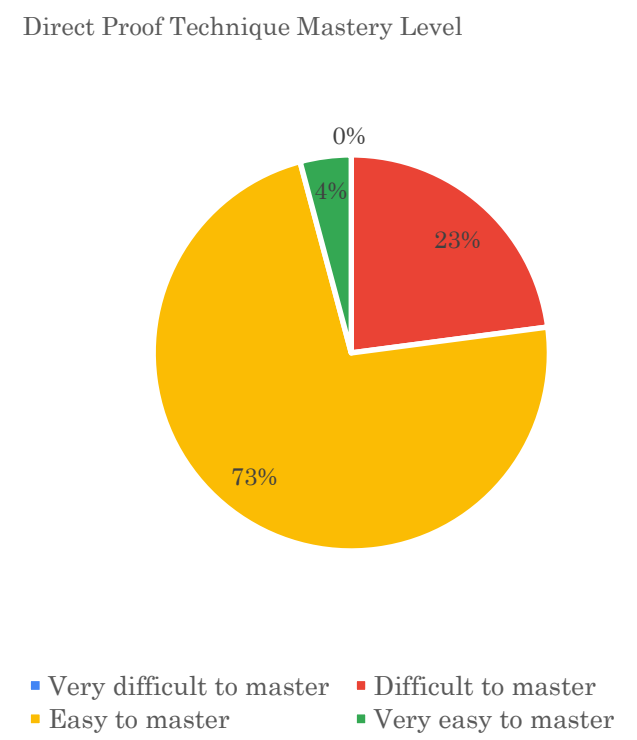

Figure 7. Level of Direct Proof Technique Mastery

According to Figure 7, most students are easily master the direct proof technique. Consequently, they are capable to apply this technique. This is implied that the textbook they read has worked. See back to the Table 1 . What they read greatly contributes to their knowledge and experience. The proportion of direct proof techniques in the reference textbooks is very influential on the student's skill to apply it. Not all techniques get this proportion in the textbook, in the Table 1.

Based on Figure 8 and Figure 9, it can be seen that more than half of all students can understand and master the contraposition proofing techniques. This means more than half of all students are skilled in applying contraposition proofing technique. Moreover, these results give fourth position of all techniques.
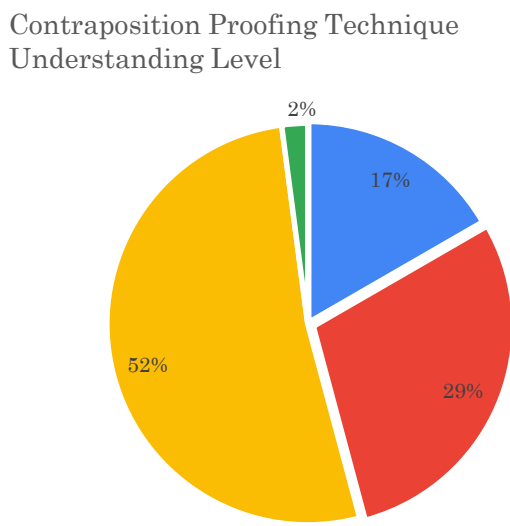

- Very difficult to understand - Difficult to understand

Figure 8. Level of Contraposition Proofing Technique Understanding

Contradiction proofing technique is more easier than contraposition, but more difficult than direct proof, let see and compare Figure 6, Figure 7, Figure 8, Figure 9, Figure 10 and Figure 11. By considering Figure 10 and Figure 11, it seems that there are students who understand but have not mastered. 
Contraposition Proofing Technique

Mastery Level

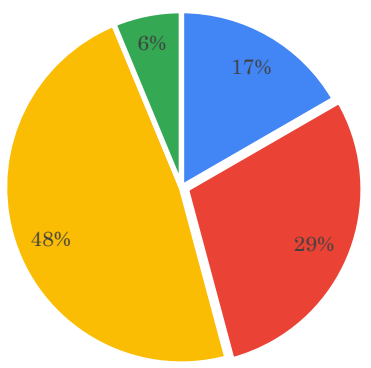

- Very difficult to master

- Difficult to master

Figure 9. Level of Contraposition Proofing Technique Mastery

\section{Contradiction Proofing Technique \\ Understanding Level}

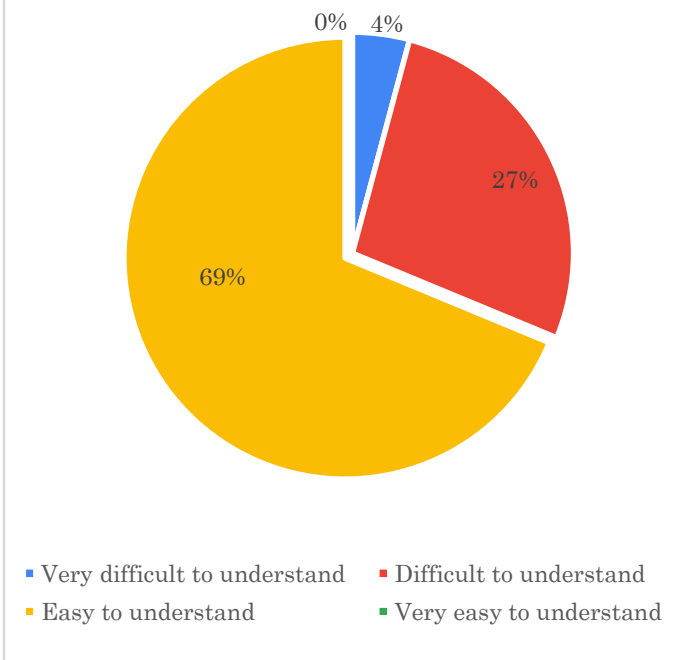

Figure 10. Level of Contradiction Proofing Technique Understanding

In addition, it was found that there were students who had difficulty understanding so they could not master it well. However, this proofing technique is the third after direct proof and mathematical induction. For the mathematical induction proofing technique can be found in Figure 12 and Figure 13.

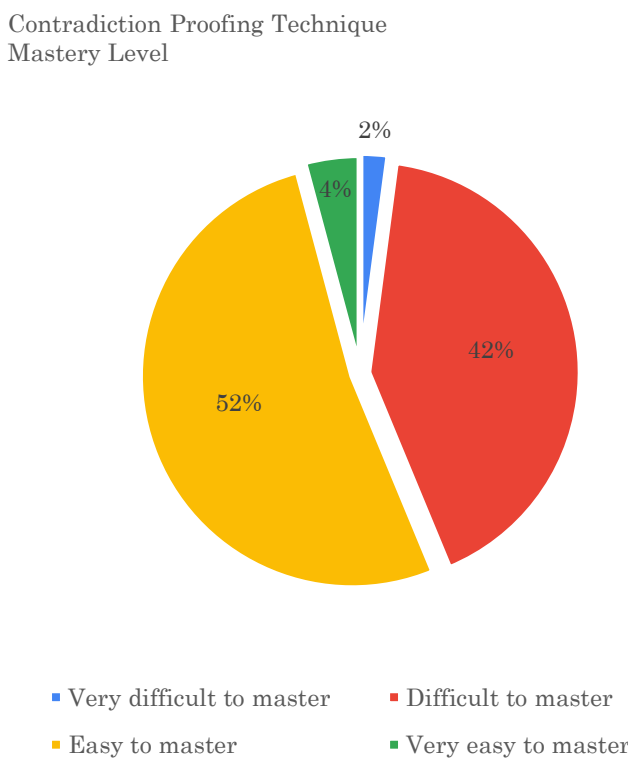

- Very difficult to master

- Difficult to master

Easy to master

- Very easy to master

Figure 11. Level of Contradiction Proofing Technique Mastery

Mathematical induction proofing technique is more difficult than direct proof, but easier than another proofing technique. By considering Figure 12 and Figure 13, 97.1\% of all students who can understand mathematical induction proofing technique, are able to master it well too. Hence, there is about $2.9 \%$ of all students who can understand it, are not able to master it well.

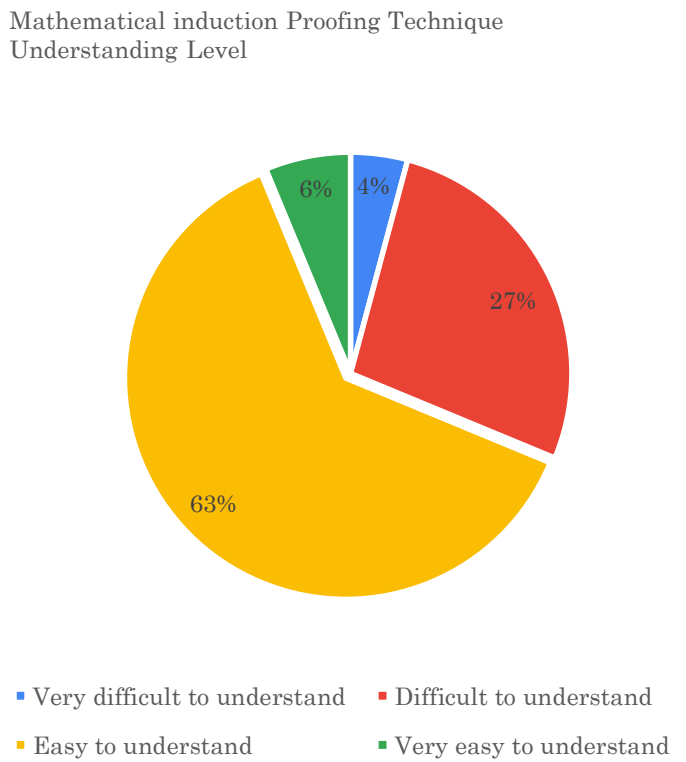

- Very difficult to understand - Difficult to understand

" Easy to understand

- Very easy to understand

Figure 12. Level of Mathematical Induction

Proofing Technique Understanding

Direct proof and mathematical induction are easier than others techniques. This is 
inseparable from the role of the textbooks they have read. As we all know, textbooks have given a very large portion to these both techniques.

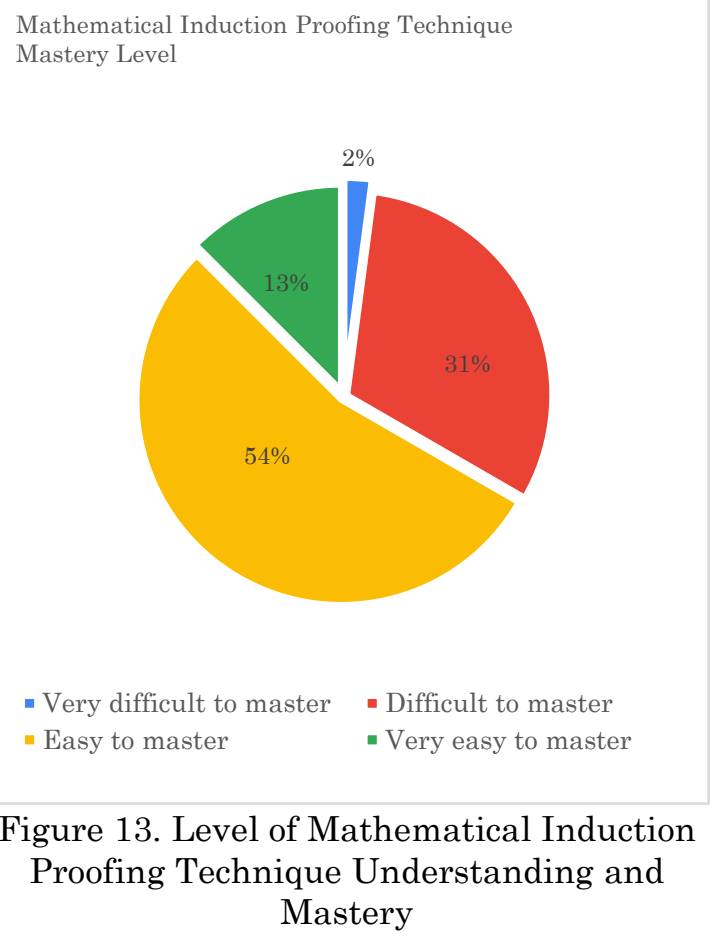

Both of these proofing techniques have been introduced since they were at high school. Unfortunately, the direct proof is not specifically discussed as is mathematical induction. Even so, the direct proof is still the easiest to understand and be mastered by students.

Here we discuss the two techniques that are difficult for student to understand and master. Both of these techniques are proof by construction and equivalent statement proof.

Let's we now look at Figure 14 and Figure 15. This figure represented level of proof by construction understanding and mastery. In this figure, it seems that very few students understand and master the proof by construction.

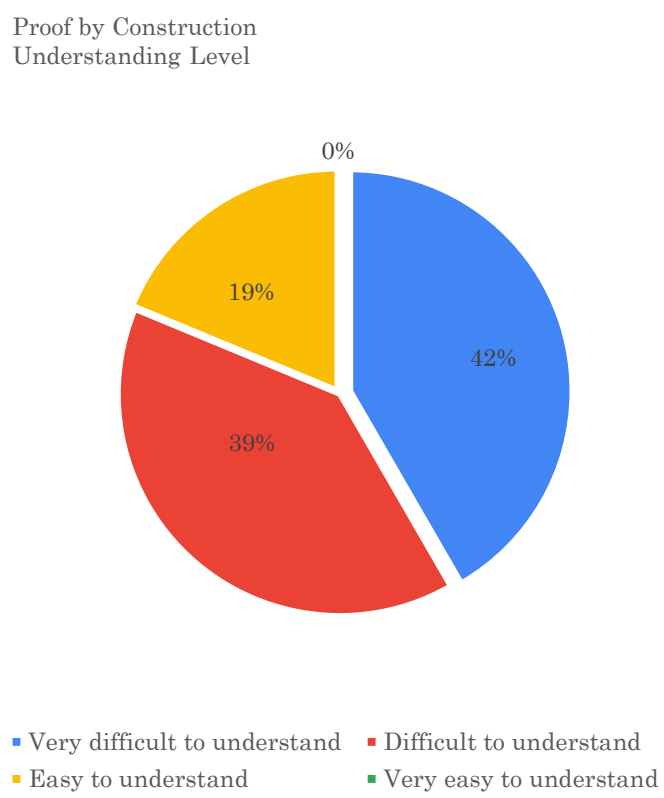

- Very difficult to understand - Difficult to understand

- Easy to understand - Very easy to understand

Figure 14. Level of Mathematical Construction Proofing Technique Understanding

This is consistent with observations in their textbooks. In Table 1, we found the multiplicity of the proof by construction of $2.96 \%$ in foreign textbook and $1.69 \%$ in domestic textbook. Very little presentation of this technique, causing their lack of understanding and mastery. As a result, they are not able to apply it properly.

Proof by Construction

Mastery Level

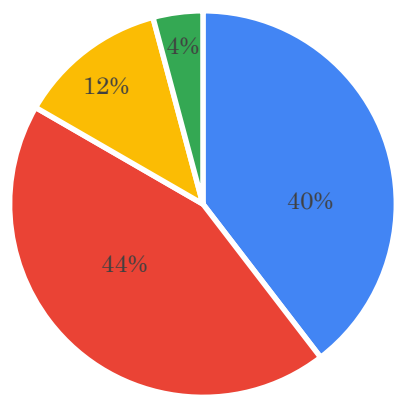

- Very difficult to master

- Difficult to master

Figure 15. Level of Mathematical Construction Proofing Technique Mastery 
Based on the explanation above, selection of textbooks is very important to support students' understanding and mastery of proofing technique. The choice text book must present all the desired techniques in full from all understanding and mastery aspect.

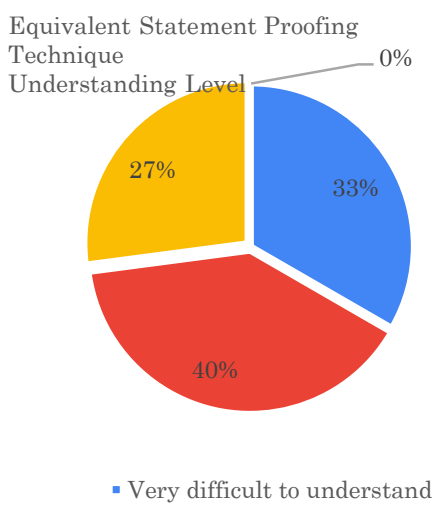

- Very difficult to understand

Figure 16. Level of Equivalent Statement Proof Technique Understanding

In proving an equivalent statement, another proofing ability is needed. This becomes its own obstacle when we don't master the required techniques. In relation to the facts obtained, most students have difficulty applying this technique, cause of not all other techniques are mastered.

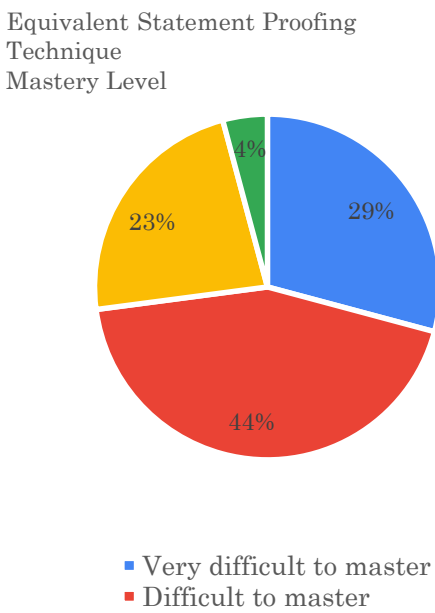

- Very difficult to master

- Difficult to master

Figure 17. Level of Equivalent Statement Proof Technique Mastery
Another fact shows that there are students who already understand the proofing technique but not yet master it well. They have difficulty in applying the techniques they already understand. The obstacles they face when applying proof techniques are:

1. Language constraints in capturing the content of the problem must be proven.

2. Systematics of poor writing.

3. Difficulty in expressing key ideas in proofing.

4. Difficulty in determining the right technique when proving statements so the resulting steps are too long.

5. Difficulties in deciphering information and finding what is needed in proof.

6. Lack of the material mastery in proofing.

\section{Language aspect and writing systematics in the proving process}

There is a linkage between the use of language and writing systematics in proving process. This is reinforced by the participant's response which states that the language used is easy to understand, uses appropriate and standard words and terms, and uses effective sentences efficiently, see Figure 18. These statements were expressed when confirming the observations of the language aspect of their textbook.

Moreover, writing the proofs systematically also determine in the process of understanding and mastery in proving. Key ideas are needed so that the writing flow can be well ordered. To complete the proof, need to explore the capability and connect between information obtained and hence the proof looks seamless. 


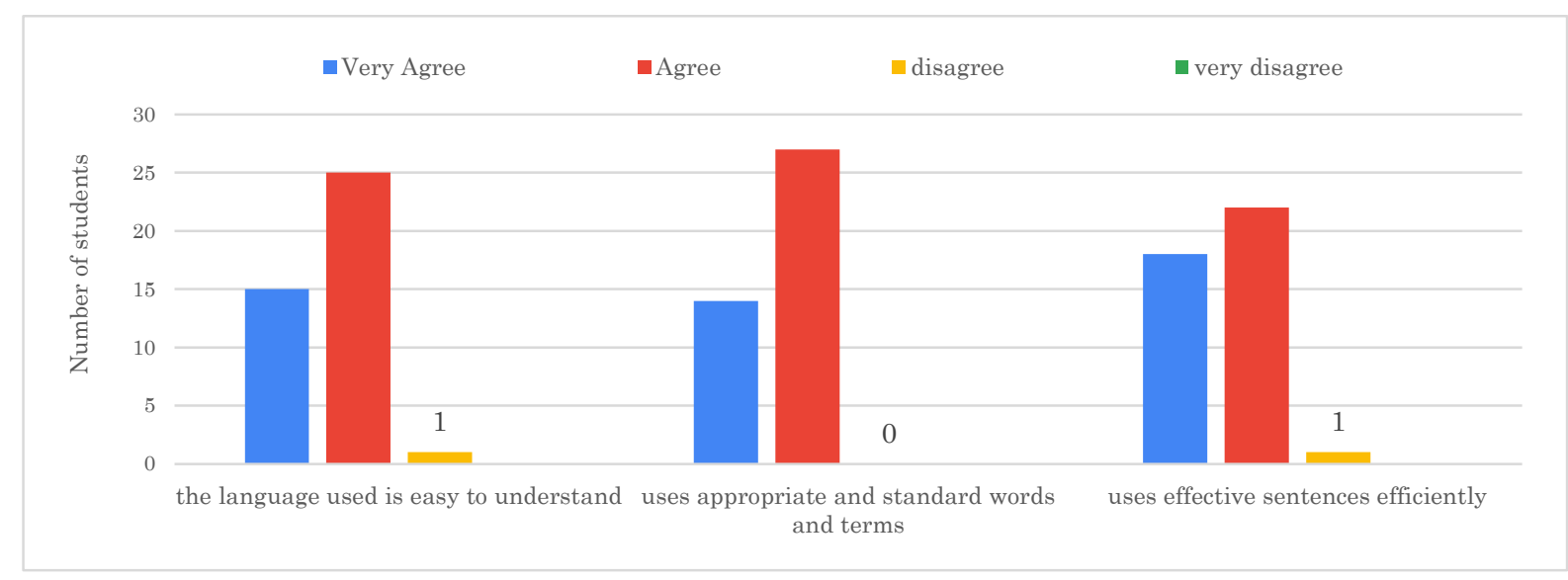

Figure 18. Language Aspect in Proving

After comparing observations results on the algebraic textbook and students, there are found following fact.

1. Implementation of equivalent statement proofing technique and proof by construction in the student's reference textbook are still very little.

2. The language aspect of the students' proofs is still not standard and hence it is difficult to understand well.

3. The proofs are written not systematically.

4. Students very difficult in applying the proofing technique by construction method and for equivalent statements.

5. Students have difficult to choose an appropriate technique in proofing process.

Another fact shows that not all the proofing techniques were used in the proofing process in the algebraic structure research. They tended to use the same technique in every proofing activity.

This might be due to mastery of proofing techniques, preferences for certain proofing techniques, lack of information about the development of various proofing techniques. The resulting impact can be identified from the steps of proofing, meanwhile, if it is conducted using another technique, it can reduce the steps, is more acceptable also comprehensible.

\section{CONCLUSION AND IMPLICATION}

From the result of the discussion above it can be concluded as follows.

There are two interrelated findings in the skills of applying proofing techniques, namely: 1) the need to refer to the textbooks that use a various proofing technique, 2) the importance of trying various techniques for each statement/ proposition. 3) The proof is need written systematically and using standard language.

Skills in applying proof techniques are greatly influenced by students' understanding/ mastery of proofing techniques and the ability to apply them.

\section{ACKNOWLEDGEMENT}

We thanks to anonymous referees for their usefull suggestion. We also thanks to IAIN Syekh Nurjati Cirebon under LP2M's research program for DIPA grants 2019.

\section{REFERENCES}

Bleiler-Baxter, S. K., \& Pair, J. D. (2017). Engaging students in roles of proof. Journal of Mathematical Behavior, 47,

16-24. 
https://doi.org/10.1016/j.jmathb.2 017.05.005

Brown, S. A. (2017). Are indirect proofs less convincing? A study of students'comparative assessments. The Journal of Mathematical Behavior, 1-23. https://doi.org/10.1016/j.jmathb.2 016.12 .010

Daepp, U., \& Gorkin, P. (2011). Reading, Writing and Proving: A Closer Look at Mathematics (2nd Edition ed.). London: Springer.

Gallian, J. A. (2017). Contemporary Abstract Algebra. Boston: Cengage Learning.

Hungerford, T. W. (2014). Abstract Algebra: An Introduction (3rd Edition ed.). Boston: Brooks/ Cole.

Lee, K. (2016). Students' proof schemes for mathematical proving anddisproving of propositions. The Journal of Mathematical Behavior, 41, 26-44. https://doi.org/10.1016/j.jmathb.2 015.11.005

Miller, D., Infante, N., \& Weber, K. (2017). How mathematicians assign points to student proofs. The Journal of Mathematical Behavior, 1-11. https://doi.org/10.1016/j.jmathb.2 017.03.002

Misri, M. A. (2017). Struktur Grup. Cirebon: CV. Confident.

Sugiyono. (2011). Metode Penelitian Pendidikan: Kuantitatif, Kualitatif dan R\&D. Bandung: Alfabeta.

Yan, X. (2019). Key ideas in a proof: The case of the irrationality of $\sqrt{ } 2$.
Journal of Mathematical

Behavior, 55, 1-10.

https://doi.org/10.1016/j.jmathb.2 019.04.001 